\title{
A generalization and improvement of Chidume theorems for total asymptotically nonexpansive mappings in Banach spaces
}

\author{
Shih-sen Chang ${ }^{1}$, Jong Kyu Kim², HW Joseph Lee ${ }^{3}$ and Chi Kin Chan ${ }^{3}$
}

\author{
* Correspondence: \\ jongkyuk@kyungnam.ac.kr \\ 2Department of Mathematics \\ Education, Kyungnam University, \\ Masan, Kyungnam 631-701, South \\ Korea \\ Full list of author information is \\ available at the end of the article
}

\begin{abstract}
The purpose of this article is to establish some new approximation theorems of common fixed points for a countable family of total asymptotically quasinonexpansive mappings in Banach spaces which generalize and improve the corresponding theorems of Chidume et al. and others.

2000 AMS Subject Classification: 47J05; 47H09; $49 J 25$.

Keywords: total asymptotically nonexpansive mapping, total asymptotically quasinonexpansive mapping, asymptotically quasi-nonexpansive mapping, asymptotically nonexpansive mapping, asymptotically nonexpansive in the intermediate sense
\end{abstract}

\section{Introduction}

Throughout this article, we assume that $E$ is a real Banach space, $C$ is a nonempty closed convex subset of $E$. In the sequel, we use $F(T)$ to denote the set of fixed points of a mapping $T$, and use $\mathfrak{R}$ and $\mathfrak{R}^{+}$to denote the set of all real numbers and the set of all nonnegative real numbers, respectively.

Recall that a mapping $T: C \rightarrow C$ is said to be nonexpansive if,

$$
\|T x-T y\| \leq\|x-y\|, \quad \forall x, y \in C \text {. }
$$

$T$ is called asymptotically nonexpansive if, there exists a sequence $\left\{v_{n}\right\} \subset(0, \infty)$ with $\lim _{n \rightarrow \infty} v_{n}=0$ such that for all $x, y \in C$

$$
\left\|T^{n} x-T^{n} y\right\| \leq\left(1+v_{n}\right)\|x-y\|, \forall n \geq 1 .
$$

The class of asymptotically nonexpansive mappings was introduced by Goebel and Kirk [1] as a generalization of the class of nonexpansive mappings. They proved that if $C$ is a nonempty closed and convex bounded subset of a real uniformly convex Banach space and $T: C \rightarrow C$ is an asymptotically nonexpansive mapping, then $T$ has a fixed point.

A mapping $T: C \rightarrow C$ is said to be asymptotically nonexpansive in the intermediate sense [2], if it is continuous and the following inequality holds:

$$
\limsup _{n \rightarrow \infty} \sup _{x, y \in C}\left(\left\|T^{n} x-T^{n} y\right\|-\|x-y\|\right) \leq 0 .
$$


If $F(T) \neq \varnothing$ and (1.1) holds for all $x \in C, y \in F(T)$, then $T$ is called asymptotically quasi-nonexpansive in the intermediate sense. Observe that if we define

$$
a_{n}:=\sup _{x, y \in C}\left(\left\|T^{n} x-T^{n} y\right\|-\|x-y\|\right) \text { and } \sigma_{n}=\max \left\{0, a_{n}\right\},
$$

then $\sigma_{n} \rightarrow 0$ as $n \rightarrow \infty$ and (1.1) reduces to

$$
\left\|T^{n} x-T^{n} y\right\| \leq\|x-y\|+\sigma_{n}, \forall x, y \in C, n \geq 1 .
$$

The class of asymptotically nonexpansive in the intermediate sense was introduced by Bruck et al. [2]. It is known [3] that if $C$ is a nonempty closed and convex bounded subset of a uniformly convex Banach space $E$ and $T: C \rightarrow C$ is asymptotically nonexpansive in the intermediate sense, then $T$ has a fixed point. It is worth mentioning that the class of mappings which are asymptotically nonexpansive in the intermediate sense contains properly the class of asymptotically nonexpansive mappings.

Recently, Alber et al. [4] introduced the concept of total asymptotically nonexpansive mappings which is more general than asymptotically nonexpansive mappings and studied the approximation methods of fixed points for this kind of mappings.

Definition 1.1 A mapping $T: C \rightarrow C$ is said to be total asymptotically nonexpansive if, there exist nonnegative real sequences $\left\{v_{n}\right\}$ and $\left\{\mu_{n}\right\}$ with $v_{n} \rightarrow 0, \mu_{n} \rightarrow 0$ as $n \rightarrow \infty$ and a strictly increasing continuous function $\zeta: \mathfrak{R}^{+} \rightarrow \mathfrak{R}^{+}$with $\zeta(0)=0$ such that for all $x, y \in C$,

$$
\left\|T^{n} x-T^{n} y\right\| \leq\|x-y\|+v_{n} \zeta(\|x-y\|)+\mu_{n}, \forall n \geq 1 .
$$

If $F(T) \neq \varnothing$ and (1.4) holds for all $x \in C, y \in F(T)$, then $T$ is called total asymptotically quasi-nonexpansive.

Remark 1.2 If $\zeta(t)=t, t \geq 0$, then (1.4) reduces to

$$
\left\|T^{n} x-T^{n} y\right\| \leq\left(1+v_{n}\right)\|x-y\|+\mu_{n}, \forall n \geq 1 .
$$

In addition, if $\mu_{n}=0, \forall n \geq 1$, then total asymptotically nonexpansive mappings coincide with asymptotically nonexpansive mappings. If $v_{n}=\mu_{n}=0, \forall n \geq 1$, then total asymptotically nonexpansive mappings coincide with nonexpansive mappings. If $v_{n}=0$ and $\mu_{n}=\sigma_{n}:=\max \left\{0, a_{n}\right\}$, where $a_{n}$ is defined by (1.2), then (1.4) reduces to (1.3) which has been studied as asymptotically nonexpansive mappings in the intermediate sense.

Within the past 30 years, research on iterative approximation of common fixed points of nonexpansive mappings, asymptotically nonexpansive mappings and asymptotically quasi-nonexpansive mappings have been considered by many authors (see, for example, [1-20] and the references therein).

Especially, recently Chidume and Ofoedu $[13,14]$ introduced the following iterative scheme for approximation of a common fixed point of a finite family of total asymptotically nonexpansive mappings in Banach spaces which extend and generalize the corresponding results of Kirk [3], Alber et al. [4], Quan et al. [5], Shahzad et al. [6], Chang et al. [9], Jung [10], Shioji et al. [11], Suzuki [12], and Schu [19].

Theorem 1.3 [[13,14]] Let $E$ be a real Banach space, $C$ be a nonempty closed convex subset of $E$ and $T_{i}: C \rightarrow C, i=1,2, \ldots, m$ be $m$ total asymptotically nonexpansive mappings with sequences $\left\{v_{i n}\right\},\left\{\mu_{i n}\right\}, i=1,2, \ldots, m$, such that $\mathfrak{F}:=\bigcap_{i=1}^{m} F\left(T_{i}\right) \neq \emptyset$. Let $\left\{x_{n}\right\}$ be defined by 


$$
\begin{aligned}
& \left\{\begin{array}{l}
x_{1} \in C, \\
x_{n+1}=\left(1-\alpha_{n}\right) x_{n}+\alpha_{n} T_{1}^{n} x_{n}, \text { if } m=1, n \geq 1
\end{array}\right. \\
& \left\{\begin{array}{l}
x_{1} \in C ; \\
x_{n+1}=\left(1-\alpha_{n}\right) x_{n}+\alpha_{n} T_{1}^{n} y_{1 n} \\
y_{1 n}=\left(1-\alpha_{n}\right) x_{n}+\alpha_{n} T_{2}^{n} y_{2 n} \\
\vdots \\
y_{(m-2) n}=\left(1-\alpha_{n}\right) x_{n}+\alpha_{n} T_{m-1}^{n} y_{(m-1) n} \\
y_{(m-1) n}=\left(1-\alpha_{n}\right) x_{n}+\alpha_{n} T_{m}^{n} x_{n}, \text { if } m \geq 2, n \geq 1 .
\end{array}\right.
\end{aligned}
$$

Suppose $\sum_{n=1}^{\infty} v_{i n}<\infty, \sum_{n=1}^{\infty} \mu_{i n}<\infty, i=1,2, \ldots, m$ and suppose that there exist $M_{i}, M_{i}^{*}>0$ such that $\zeta_{i}\left(\lambda_{i}\right) \leq M_{i}^{*} \lambda_{i}$ for all $\lambda_{i} \geq M_{i}, i=1,2, \ldots, m$. Then the sequence $\left\{x_{n}\right\}$ is bounded and $\lim _{n \rightarrow \infty}\left\|x_{n}-p\right\|$ exists, $p \in \mathfrak{F}$. Moreover, the sequence $\left\{x_{n}\right\}$ converges strongly to a common fixed point of $T_{i}, i=1,2, \ldots, m$ if and only if $\liminf _{n \rightarrow \infty} d\left(x_{n}, \mathfrak{F}\right)=0$, where $d\left(x_{n}, \mathfrak{F}\right)=\inf _{y \in \mathfrak{F}}|| x_{n}-y \|, n \geq 1$.

Theorem 1.4 [[13,14]] Let $E$ be a uniformly convex real space, $C$ be a nonempty closed convex subset of $E$, and $T_{i}: C \rightarrow C, i=1,2, \ldots, m$ be $m$ uniformly continuous total asymptotically nonexpansive mappings with sequences $\left\{v_{i n}\right\},\left\{\mu_{i n}\right\} \subset[0, \infty)$ such that $\sum_{n=1}^{\infty} v_{i n}<\infty, \sum_{n=1}^{\infty} \mu_{i n}<\infty, i=1,2, \ldots, m$ and $\mathfrak{F}:=\bigcap_{i=1}^{m} F\left(T_{i}\right) \neq \emptyset$. Let $\left\{\alpha_{i n}\right\} \subset$ $[\varepsilon, 1-\varepsilon]$ for some $\varepsilon \in(0,1)$. From arbitrary $x_{1} \in C$, define the sequence $\left\{x_{n}\right\}$ by $(1.5)$. Suppose that there exist $M_{i}, M_{i}^{*}>0$ such that $\zeta_{i}\left(\lambda_{i}\right) \leq M_{i}^{*} \lambda_{i}$ whenever $\lambda_{i} \geq M_{i}, i=1$, $2, \ldots, m$ and that one of $T_{1}, T_{2}, \ldots, T_{m}$ is compact, then $\left\{x_{n}\right\}$ converges strongly to some $p \in \mathfrak{F}$.

It is our purpose in this article to construct a new iterative sequence much simpler than (1.5) for approximation of common fixed points of a countable family of total asymptotically nonexpansive mappings and give necessary and sufficient conditions for the convergence of the scheme to common fixed points of the mappings in arbitrary real Banach spaces. As well as a sufficient condition for convergence of the iteration process to a common fixed point of mappings under the setting of uniformly convex Banach space is also established. The results presented in the article not only generalize and improve the corresponding results of Chidume et al. [13-15] but also unify, extend and generalize the corresponding result of $[3-7,9-12,19]$.

\section{Preliminaries}

For the sake of convenience we first give the following lemmas which will be needed in proving our main results.

Lemma 2.1 [[20]] Let $E$ be a uniformly convex Banach space, $r>0$ be a positive number and $B_{r}(0)$ be a closed ball of $E$. Then, for any sequence $\left\{x_{i}\right\}_{i=1}^{\infty} \subset B_{r}(0)$ and for any sequence $\left\{\lambda_{i}\right\}_{i=1}^{\infty}$ of positive numbers with $\sum_{n=1}^{\infty} \lambda_{n}=1$, there exists a continuous, strictly increasing and convex function $g:[0,2 r) \rightarrow[0, \infty), g(0)=0$ such that for any positive integers $i, j \geq 1, i \neq j$, the following holds:

$$
\left\|\sum_{n=1}^{\infty} \lambda_{n} x_{n}\right\|^{2} \leq \sum_{n=1}^{\infty} \lambda_{n}\left\|x_{n}\right\|^{2}-\lambda_{i} \lambda_{j} g\left(\left\|x_{i}-x_{j}\right\|\right) .
$$

Lemma 2.2 Let $\left\{a_{n}\right\},\left\{b_{n}\right\}$, and $\left\{\lambda_{n}\right\}$ be sequences of nonnegative real numbers such that 


$$
a_{n+1} \leq\left(1+\lambda_{n}\right) a_{n}+b_{n}, \forall n \geq n_{0}
$$

where $n_{0}$ is some positive integer. If $\sum_{n=1}^{\infty} \lambda_{n}<\infty$ and $\sum_{n=1}^{\infty} b_{n}<\infty$, then $\left\{a_{n}\right\}$ is bounded and $\lim _{n \rightarrow \infty} a_{n}$ exists. Moreover, if, in addition, $\lim _{\inf _{n \rightarrow \infty}} a_{n}=0$, then $\lim _{n \rightarrow \infty} a_{n}=0$.

\section{Main results}

Definition 3.1 Let $E$ be a real Banach space, $C$ be a nonempty closed convex subset of E.

(1) Let $\left\{T_{i}\right\}$ be a countable family of mappings from $C$ into itself. $\left\{T_{i}\right\}$ is said to be uniformly total asymptotically quasi-nonexpansive mappings if, $\mathfrak{F}:=\bigcap_{i=1}^{\infty} F\left(T_{i}\right) \neq \emptyset$, and there exist nonnegative real sequences $\left\{v_{n}\right\}$ and $\left\{\mu_{n}\right\}$ with $v_{n} \rightarrow 0, \mu_{n} \rightarrow 0$ as $n \rightarrow \infty$ and a strictly increasing continuous function $\zeta: \mathfrak{R}^{+} \rightarrow \mathfrak{R}^{+}$with $\zeta(0)=0$ such that for all $x \in C, p \in \mathfrak{F}$,

$$
\left\|T_{i}^{n} x-p\right\| \leq\|x-p\|+v_{n} \zeta(\|x-p\|)+\mu_{n}, \forall i \geq 1, n \geq 1 .
$$

(2) A mapping $T: C \rightarrow C$ is said to be uniformly L-Lipschitz continuous, if there exists a constant $L>0$ such that

$$
\left\|T^{n} x-T^{n} y\right\| \leq L\|x-y\|, \forall x, y \in C, \forall n \geq 1 .
$$

Let $\left\{T_{i}\right\}$ be a countable family of uniformly total asymptotically quasi-nonexpansive mappings from $C$ into itself and for each $i \geq 1, T_{i}$ is uniformly $L_{i}$-Lipschitz continuous. For any given $x_{0} \in C$, we define an iterative sequence $\left\{x_{n}\right\}$ by

$$
\left\{\begin{array}{l}
x_{0} \in C \text { chosen arbitrary, } \\
x_{n+1}=\alpha_{n} x_{n}+\left(1-\alpha_{n}\right) z_{n}, \\
z_{n}=\beta_{n, 0} x_{n}+\sum_{i=1}^{\infty} \beta_{n, i} T_{i}^{n} x_{n}, \quad \forall n \geq 0 .
\end{array}\right.
$$

Theorem 3.2 Let $E$ be a real Banach space, $C$ be a nonempty closed convex subset of $E$. Let $\left\{T_{n}\right\}_{n=1}^{\infty}$ be a countable family of uniformly total asymptotically quasi-nonexpansive mappings from $C$ into itself with nonnegative real sequences $\left\{v_{n}\right\}$ and $\left\{\mu_{n}\right\}$ and a strictly increasing continuous function $\zeta: \mathfrak{R}^{+} \rightarrow \mathfrak{R}^{+}$such that $\zeta(0)=0$, $\mathfrak{F}:=\bigcap_{i=1}^{m} F\left(T_{i}\right) \neq \emptyset$ and $\sum_{n=1}^{\infty}\left(v_{n}+\mu_{n}\right)<\infty$. Let $\left\{x_{n}\right\}$ be the sequence defined by (3.2), where $\left\{\beta_{n, i}\right\}, i=0,1,2, \ldots$ and $\left\{\alpha_{n}\right\}$ are sequences in $[0,1]$ satisfying the following conditions:

(a) for each $n \geq 0, \sum_{i=0}^{\infty} \beta_{n, i}=1$; If $\left\{x_{n}\right\}$ and $\mathfrak{F}$ are bounded, then the following conclusions hold:

(1) for each $p \in \mathfrak{F}, \lim _{n \rightarrow \infty}\left\|x_{n}-p\right\|$ exists;

(2) the sequence $\left\{x_{n}\right\}$ converges strongly to a common fixed point $x^{*} \in \mathfrak{F}$ if and only if $\liminf _{n \rightarrow \infty} d\left(x_{n}, \mathfrak{F}\right)=0$, where $d\left(x_{n}, \mathfrak{F}\right)=\inf _{y \in \mathfrak{F}}|| x_{n}-y \|, n \geq 1$.

Proof. (1) For any $n \geq 0$ and for any given $p \in \mathfrak{F}$ we have

$$
\left\|x_{n+1}-p\right\| \leq \alpha_{n}|| x_{n}-p\left\|+\left(1-\alpha_{n}\right)\right\| z_{n}-p \| .
$$


Denoting by $M=\sup _{n \geq 0, p \in \mathfrak{F}}\left\{|| x_{n}\|+\| x_{n}-p \|\right\}<\infty$, from (3.2) we have

$$
\begin{aligned}
& \left\|z_{n}-p\right\| \leq \beta_{n, 0}\left\|x_{n}-p\right\|+\sum_{i=1}^{\infty} \beta_{n, i}\left\|T_{i}^{n} x_{n}-p\right\| \\
& \leq \beta_{n, 0}\left\|x_{n}-p\right\|+\sum_{i=1}^{\infty} \beta_{n, i}\left[\left\|x_{n}-p\right\|+v_{n} \zeta\left(\left\|x_{n}-p\right\|\right)+\mu_{n}\right] \\
& \leq \beta_{n, 0}|| x_{n}-p \|+\sum_{i=1}^{\infty} \beta_{n, i}\left[\left\|x_{n}-p\right\|+v_{n} \zeta(M)+\mu_{n}\right] \\
& \leq\left\|x_{n}-p\right\|+\gamma_{n},
\end{aligned}
$$

where $\gamma_{n}=v_{n} \zeta(M)+\mu_{n}$. By the assumption, $\sum_{n=1}^{\infty} \gamma_{n}<\infty$. Substituting (3.4) into (3.3) and simplifying we have

$$
\left\|x_{n+1}-p\right\| \leq\left\|x_{n}-p\right\|+\gamma_{n}, \forall n \geq 1 \text { and for each } p \in \mathfrak{F} .
$$

It follows from Lemma 2.2 that $\lim _{n \rightarrow \infty}\left\|x_{n}-p\right\|$ exists. The conclusion (1) is proved.

(2) From (3.5) we have that

$$
d\left(x_{n+1}, \mathfrak{F}\right) \leq d\left(x_{n}, \mathfrak{F}\right)+\gamma_{n}, \text { for each } n \geq 1 .
$$

Then Lemma 2.2 implies that $\lim _{n \rightarrow \infty} d\left(x_{n}, \mathfrak{F}\right)$ exists. By the assumption that $\liminf _{n \rightarrow \infty} d\left(x_{n}, \mathfrak{F}\right)=0$, therefore we have $\lim _{n \rightarrow \infty} d\left(x_{n}, \mathfrak{F}\right)=0$.

This completes the proof of Theorem 3.2.

Theorem 3.3 Let $E, C,\left\{T_{n}\right\}_{n=1}^{\infty}, \mathfrak{F}$ be the same as in Theorem 3.2. If there exist constants $K, K^{*}>0$ such that $\zeta(t) \leq K^{*} t, \forall t \geq K$, then the sequence $\left\{x_{n}\right\}$ defined by (3.2) is bounded and so the conclusions of Theorem 3.2 still hold.

Proof In fact, from (3.2) for any given $p \in \mathfrak{F}$, we have that

$$
\begin{aligned}
\left\|z_{n}-p\right\| & \leq \beta_{n, 0}\left\|x_{n}-p\right\|+\sum_{i=1}^{\infty} \beta_{n, i}\left\|T_{i}^{n} x_{n}-p\right\| \\
& \leq \beta_{n, 0}\left\|x_{n}-p\right\|+\sum_{i=1}^{\infty} \beta_{n, i}\left\{\left\|x_{n}-p\right\|+v_{n} \zeta\left(\left\|x_{n}-p\right\|\right)+\mu_{n}\right\}
\end{aligned}
$$

By the assumption, it is easy to see that

$$
\zeta\left(\left\|x_{n}-p\right\|\right) \leq \begin{cases}\zeta(K), & \text { if }\left\|x_{n}-p\right\|<K \\ K^{*}|| x_{n}-p \|, & \text { if }\left\|x_{n}-p\right\| \geq K .\end{cases}
$$

This implies that

$$
\zeta\left(\left\|x_{n}-p\right\|\right) \leq \zeta(K)+K^{*}|| x_{n}-p \| .
$$

Therefore, we have

$$
\begin{aligned}
\left\|z_{n}-p\right\| & \leq \beta_{n, 0}|| x_{n}-p \|+\sum_{i=1}^{\infty} \beta_{n, i}\left\{\left\|x_{n}-p\right\|+v_{n}\left[\zeta(K)+K^{*}\left\|x_{n}-p\right\|\right]+\mu_{n}\right\} \\
& \leq\left(1+v_{n} K^{*}\right)\left\|x_{n}-p\right\|+\xi_{n}
\end{aligned}
$$


where $\xi_{n}=v_{n} \zeta(K)+\mu_{n}$. Substituting (3.6) into (3.3) and simplifying, we have that

$$
\left\|x_{n+1}-p\right\| \leq\left(1+v_{n} K^{*}\right)\left\|x_{n}-p\right\|+\xi_{n}, \forall n \geq 1 .
$$

By Lemma 2.2, for each $p \in \mathfrak{F}, \lim _{n \rightarrow \infty}\left\|x_{n}-p\right\|$ exists, and so $\left\{x_{n}\right\}$ is bounded. The conclusions of Theorem 3.3 can be obtained from Theorem 3.2 immediately.

From Theorem 3.3 we can obtain the following result:

Corollary 3.4 Let $E, C$ be as in Theorem 3.2. Let $T_{i}: C \rightarrow C, i=1,2, \ldots, m$ be $m$ total asymptotically quasi-nonexpansive mappings with nonnegative real sequences $\left\{v_{i n}\right\},\left\{\mu_{i n}\right\}$ and a strictly increasing continuous function $\zeta_{i}: \mathfrak{R}^{+} \rightarrow \mathfrak{R}^{+}$with $\zeta_{i}(0)=0$ such that $\mathfrak{F}:=\bigcap_{i=1}^{m} F\left(T_{i}\right)$ is nonempty and bounded, $\sum_{n=1}^{\infty}\left(v_{i n}+\mu_{i n}\right)<\infty, i=1,2$, $\ldots, m$. Let $\left\{x_{n}\right\}$ be the sequence defined by:

$$
\left\{\begin{array}{l}
x_{0} \in C \text { chosen arbitrary, } \\
x_{n+1}=\alpha_{n} x_{n}+\left(1-\alpha_{n}\right) z_{n} \\
z_{n}=\beta_{n, 0} x_{n}+\sum_{i=1}^{m} \beta_{n, i} T_{i}^{n} x_{n}, \quad \forall n \geq 0
\end{array}\right.
$$

where $\left\{\beta_{n, i}\right\}, i=0,1,2, \ldots, m$, and $\left\{\alpha_{n}\right\}$ are sequences in $[0,1]$ satisfying the following conditions:

(a) for each $n \geq 0, \sum_{i=0}^{m} \beta_{n, i}=1$;

If there exist constants $K, K^{*}>0$ such that for each $i=1,2, \ldots, m, \zeta_{i}(t) \leq K^{*} t, \forall t \geq K$, then $\left\{x_{n}\right\}$ is bounded and the conclusions of Theorem 3.2 still hold.

Proof Let $v_{n}=\max _{1 \leq i \leq m} v_{i n}, \mu_{n}=\max _{1 \leq i \leq m} \mu_{i n}$ and $\zeta=\max _{1 \leq i \leq m} \zeta_{i}$, then $\sum_{n=1}^{\infty}\left\{v_{n}+\mu_{n}\right\}<\infty$ and $\zeta: \mathfrak{R}^{+} \rightarrow \mathfrak{R}^{+}$is a strictly increasing continuous function with $\zeta(0)=0$ and there exist constants $K, K^{*}>0$ such that $\zeta(t) \leq K^{*} t, \forall t \geq K$. Therefore all conditions in Theorem 3.3 are satisfied. The conclusions of Corollary 3.4 can be obtained from Theorem 3.3 immediately.

If the space $E$ is uniformly convex, and one of $\left\{T_{i}\right\}$ is compact, then we can obtain the following more better result.

Theorem 3.5 Let $E$ be a uniformly convex real Banach space, $C$ be a nonempty closed convex subset of $E$ and $\left\{T_{i}\right\}_{i=1}^{\infty}$ be a countable family of uniformly total asymptotically quasi-nonexpansive mappings from $C$ into itself with nonnegative real sequences $\left\{v_{n}\right\}$ and $\left\{\mu_{n}\right\}$ and a strictly increasing continuous function $\zeta: \mathfrak{R}^{+} \rightarrow \mathfrak{R}^{+}$such that $\zeta(0)$ $=0, \mathfrak{F}:=\bigcap_{i=1}^{\infty} F\left(T_{i}\right) \neq \emptyset$ and $\sum_{n=1}^{\infty}\left(v_{n}+\mu_{n}\right)<\infty$, and for each $i \geq 1, T_{i}$ is uniformly $L i$-Lipschitzian continuous. Let $\left\{x_{n}\right\}$ be the sequence defined by (3.2), where $\left\{\beta_{n, i}\right\}, i=$ $0,1,2, \ldots$ and $\left\{\alpha_{n}\right\}$ are sequences in $[0,1]$ satisfying the conditions (a), (b) in Theorem 3.2 and $\lim \inf \beta_{n, 0} \beta_{n ; i}>0$ for any $i \geq 1$. If $\left\{x_{n}\right\}$ and $\mathfrak{F}$ both are bounded and one of $\left\{T_{i}\right\}$ is compact, then the following conclusions hold:

(1) $\lim _{n \rightarrow \infty}|| x_{n}-T_{j}^{n} x_{n} \|=0$ uniformly in $j \geq 1$,

(2) the sequence $\left\{x_{n}\right\}$ converges strongly to some point $p \in \mathfrak{F}$.

Proof (1) Since $\left\{x_{n}\right\}$ and $\mathfrak{F}$ both are bounded and the norm $\|\cdot\|^{2}$ is convex, for any given $p \in \mathfrak{F}$, it follows from (3.2) that

$$
\begin{aligned}
\left\|x_{n+1}-p\right\|^{2} & =\left\|\alpha_{n} x_{n}+\left(1-\alpha_{n}\right) z_{n}-p\right\|^{2} \\
& \leq \alpha_{n}\left\|x_{n}-p\right\|^{2}+\left(1-\alpha_{n}\right)\left\|z_{n}-p\right\|^{2} .
\end{aligned}
$$


By Lemma 2.1, for any positive integer $j \geq 1$ we have

$$
\begin{aligned}
\left\|z_{n}-p\right\|^{2}= & \left\|\beta_{n, 0} x_{n}+\sum_{i=1}^{\infty} \beta_{n, i} T_{i}^{n} x_{n}-p\right\|^{2} \\
\leq & \beta_{n, 0}\left\|x_{n}-p\right\|^{2}+\sum_{i=1}^{\infty} \beta_{n, i}\left\|T_{i}^{n} x_{n}-p\right\|^{2} \\
& -\beta_{n, 0} \beta_{n, j} g\left(\left\|x_{n}-T_{j}^{n} x_{n}\right\|\right) .
\end{aligned}
$$

Since

$$
\begin{aligned}
\left\|T_{i}^{n} x_{n}-p\right\|^{2} & \leq\left(\left\|x_{n}-p\right\|+v_{n} \zeta\left(\left\|x_{n}-p\right\|\right)+\mu_{n}\right)^{2} \\
& \leq\left(\left\|x_{n}-p\right\|+v_{n} \zeta(M)+\mu_{n}\right)^{2} \\
& \leq\left\|x_{n}-p\right\|^{2}+\gamma_{n}
\end{aligned}
$$

where

$$
\begin{aligned}
& M=\sup _{n \geq 1, p \in \mathfrak{F}}\left\|x_{n}-p\right\|, \\
& \gamma_{n}=\left(v_{n} \zeta(M)+\mu_{n}\right)\left(v_{n} \zeta(M)+\mu_{n}+2 M\right) \rightarrow 0(\text { as } n \rightarrow \infty)
\end{aligned}
$$

First substituting (3.11) into (3.10), then substituting (3.10) into (3.9) and simplifying we have that

$$
\begin{aligned}
\left\|x_{n+1}-p\right\|^{2} \leq & \alpha_{n}\left\|x_{n}-p\right\|^{2}+\left(1-\alpha_{n}\right)\left\{\beta_{n, 0}\left\|x_{n}-p\right\|^{2}\right. \\
& \left.+\sum_{i=1}^{\infty} \beta_{n, i}\left(\left\|x_{n}-p\right\|^{2}+\gamma_{n}\right)-\beta_{n, 0} \beta_{n, j} g\left(\left\|x_{n}-T_{j}^{n} x_{n}\right\|\right)\right\} \\
\leq & \alpha_{n}\left\|x_{n}-p\right\|^{2}+\left(1-\alpha_{n}\right)\left\{\left\|x_{n}-p\right\|^{2}+\gamma_{n}-\beta_{n, 0} \beta_{n, j} g\left(\left\|x_{n}-T_{j}^{n} x_{n}\right\|\right)\right\} \\
\leq & \left.\left\|x_{n}-p\right\|^{2}+\gamma_{n}-\left(1-\alpha_{n}\right) \beta_{n, 0} \beta_{n, j} g\left(\left\|x_{n}-T_{j}^{n} x_{n}\right\|\right)\right\} .
\end{aligned}
$$

This together with Theorem 3.2 (1) shows that for each $j \geq 1$

$$
\left(1-\alpha_{n}\right) \beta_{n, 0} \beta_{n, j} g\left(\left\|x_{n}-T_{j}^{n} x_{n}\right\|\right) \leq\left\|x_{n}-p\right\|^{2}+\gamma_{n}-\left\|x_{n+1}-p\right\|^{2} \rightarrow 0(\text { as } n \rightarrow \infty) .
$$

By conditions (b) and $\lim \inf \beta_{n, 0} \beta_{n, i}>0$ for any $i \geq 1$, this implies that

$$
\lim _{n \rightarrow \infty} g\left(\left\|x_{n}-T_{j}^{n} x_{n}\right\|\right)=0 \text { uniformly in } j \geq 1 \text {. }
$$

By the property of $g$, we have that

$$
\lim _{n \rightarrow \infty}\left\|x_{n}-T_{j}^{n} x_{n}\right\|=0 \text { uniformly in } j \geq 1 \text {. }
$$

The conclusion (1) is proved.

(2) From (3.2) we have

$$
\left\|x_{n+1}-x_{n}\right\|=\left(1-\alpha_{n}\right)\left\|z_{n}-x_{n}\right\| \leq \sum_{i=1}^{\infty} \beta_{n, i}\left\|T_{i}^{n} x_{n}-x_{n}\right\| .
$$

For any given $\varepsilon>0$, from (3.12) there exists a positive integer $n_{0}$ such that

$$
\left\|x_{n}-T_{i}^{n} x_{n}\right\|<\varepsilon \text { for all } n \geq n_{0}, \text { and any } i \geq 1 \text {. }
$$


This together with (3.13) yields that

$$
\left\|x_{n+1}-x_{n}\right\| \rightarrow 0(\text { as } n \rightarrow \infty) .
$$

By the assumption that, there exists a mapping in $\left\{T_{i}\right\}$ which is compact. Without loss of generality, we can assume that $T_{1}$ is compact. Thus, there exists a subsequence $\left\{T_{1}^{n_{k}} x_{n_{k}}\right\}$ of $\left\{T_{1}^{n} x_{n}\right\}$ such that $T_{1}^{n_{k}} x_{n_{k}} \rightarrow x^{*}($ as $k \rightarrow \infty)$ for some point $x^{*} \in C$. Since $T_{1}$ is $L_{1}$-Lipschitzian, it is continuous. Thus we have $T_{1} T_{1}^{n_{k}} x_{n_{k}} \rightarrow T_{1} x^{*}$ (as $k \rightarrow \infty$ ). From (3.12), we have that $\lim _{k \rightarrow \infty} x_{n_{k}}=x^{*}$ Also from (3.12) for each $i \geq 1, \lim _{k \rightarrow \infty} T_{i}^{n_{k}} x_{n_{k}}=x^{*}$. Thus for each $i \geq 1, \lim _{k \rightarrow \infty} T_{i} T_{i}^{n_{k}} x_{n_{k}}=T_{i} x^{*}$. By (3.14), $\lim _{k \rightarrow \infty}\left\|x_{n_{k}+1}-x_{n_{k}}\right\|=0$, it follows that $\lim _{k \rightarrow \infty} x_{n_{k}+1}=x^{*}$. Next, we prove that $x^{*} \in \mathfrak{F}$. In fact, for each $i \geq 1$, since $T_{i}$ is uniformly $L_{i}$-Lipschitz continuous, we have

$$
\begin{aligned}
\left\|x^{*}-T_{i} x^{*}\right\| & \leq\left\|x^{*}-x_{n_{k}+1}\right\|+\left\|x_{n_{k}+1}-T_{i}^{n_{k}+1} x_{n_{k}+1}\right\| \\
& +\left\|T_{i}^{n_{k}+1} x_{n_{k}+1}-T_{i}^{n_{k}+1} x_{n_{k}}\right\|+\left\|T_{i}^{n_{k}+1} x_{n_{k}}-T_{i} x^{*}\right\| \\
& \leq\left\|x^{*}-x_{n_{k}+1}\right\|+\left\|x_{n_{k}+1}-T_{i}^{n_{k}+1} x_{n_{k}+1}\right\| \\
& +L_{i}\left\|x_{n_{k}+1}-x_{n_{k}}\right\|+\left\|T_{i}^{n_{k}+1} x_{n_{k}}-T_{i} x^{*}\right\| \rightarrow 0(\text { as } k \rightarrow \infty) .
\end{aligned}
$$

Therefore, we have $x^{*}=T_{i} x^{*}$, for each $i \geq 1$. This implies that $x^{*} \in \mathfrak{F}$. But by Theorem 3.2, for each $p \in \mathfrak{F}, \lim _{n \rightarrow \infty}\left\|x_{n}-p\right\|$ exists. Hence $\left\{x_{n}\right\}$ converges strongly to $x^{*} \in \mathfrak{F}$. This completes the proof of Theorem 3.5.

Remark 3.6 By the same way as given in the proof of Theorem 3.3, we can prove that if the condition " $\left\{x_{n}\right\}$ is bounded" in Theorem 3.5 is replaced by the condition "if there exist constants $K, K^{*}>0$ such that $\zeta(t) \leq K^{*} t, \forall t \geq K^{*}$, then the conclusions of Theorem 3.5 still hold.

Definition 3.7 Let $\left\{T_{i}\right\}$ be a family of mappings from $C$ into itself.

(1) $\left\{T_{i}\right\}$ is said to be a family of uniformly asymptotically nonexpansive mappings if, there exists a sequence of nonnegative real numbers $\left\{v_{n}\right\}$ with $v_{n} \rightarrow 0($ as $n \rightarrow \infty)$ such that for any $x, y \in C$ and for any $i \geq 1$

$$
\left\|T_{i}^{n} x-T_{i}^{n} y\right\| \leq\left(1+v_{n}\right)\|x-y\|, \quad \forall n \geq 1
$$

(2) $\left\{T_{i}\right\}$ is said to be a family of uniformly asymptotically nonexpansive in the intermediate sense if, for each $i \geq 1, T_{i}$ is continuous and there exists a sequence $\left\{\sigma_{n}\right\}$ of nonnegative real numbers with $\sigma_{n} \rightarrow 0$ (as $\left.n \rightarrow \infty\right)$ such that for any $x, y \in C$ and for any $i \geq 1$,

$$
\left\|T_{i}^{n} x-T_{i}^{n} y\right\| \leq\|x-y\|+\sigma_{n}, \forall n \geq 1 .
$$

From Theorem 3.5 and Remark 3.6 we can obtain the following

Theorem 3.8 Let $E, C$ be the same as in Theorem 3.5. Let $\left\{T_{i}\right\}$ be a countable family of uniformly asymptotically nonexpansive mappings from $C$ into itself with nonnegative real sequences $\left\{v_{n}\right\}$ such that $\mathfrak{F}:=\bigcap_{i=1}^{\infty} F\left(T_{i}\right)$ is nonempty and bounded and $\sum_{n=1}^{\infty} v_{n}<\infty$. Let $\left\{x_{n}\right\}$ be the sequence defined by (3.2), where $\left\{\beta_{n, i}\right\}, i=0,1,2$, .. and $\left\{\alpha_{n}\right\}$ are sequences in $[0,1]$ satisfying the conditions (a), (b) in Theorem 3.2 and lim $\inf \beta_{n, 0} \beta_{n, i}>0$ for any $i \geq 1$. If one of $\left\{T_{i}\right\}$ is compact, then the conclusions in Theorem 3.5 still hold:

Proof. Letting $\mu_{n}=0, \forall n \geq 1, \zeta(t)=t, t \geq 0, K=0$, and $K^{*}=1$, therefore we have $\left\|T_{i}^{n} x-T_{i}^{n} y\right\| \leq L\|x-y\|, \forall n \geq 1$, and $\zeta(t)=K^{*} t, \forall t \geq 0$. Again since $v_{n} \rightarrow 0,\left\{v_{n}\right\}$ is 
bounded. Setting $L=1+\sup _{n \geq 1} v_{n}$, it follows from (3.16) that

$$
\left\|T_{i}^{n} x-T_{i}^{n} y\right\| \leq L\|x-y\|, \forall n \geq 1,
$$

i.e., for each $i \geq 1, T_{i}$ is uniformly $L$-Lipschitz continuous. Therefore all conditions in Theorem 3.5 and Remark 3.6 are satisfied. The conclusions of Theorem 3.8 can be obtained from Theorem 3.5 and Remark 3.6 immediately.

Theorem 3.9 Let $E, C$ be the same as in Theorem 3.5. Let $\left\{T_{i}\right\}$ be a countable family of uniformly asymptotically nonexpansive in the intermediate sense from $C$ into itself with a nonnegative real sequence $\left\{\sigma_{n}\right\}$ such that $\mathfrak{F}:=\bigcap_{i=1}^{\infty} F\left(T_{i}\right)$ is nonempty and bounded and $\sum_{n=1}^{\infty} \sigma_{n}<\infty$. Let $\left\{x_{n}\right\}$ be the sequence defined by (3.2), where $\left\{\beta_{n}, i\right\}, i=$ $0,1,2, \ldots$ and $\left\{\alpha_{n}\right\}$ are sequences in $[0,1]$ satisfying the conditions (a), (b) in Theorem 3.2 and $\lim \inf \beta_{n, 0} \beta_{n, i}>0$ for any $i \geq 1$. If for each $i \geq 1, T_{i}$ is uniformly $L_{i}$-Lipschitzian continuous and one of $\left\{T_{i}\right\}$ is compact, then the conclusions in Theorem 3.5 still hold.

\section{Acknowledgements}

The authors would like to express their thanks to the referees for their helpful comments and suggestions. This work was supported by the National Research Foundation of Korean Grant funded by the Korean Government (20110002581).

\section{Author details}

${ }^{1}$ Department of Mathematics, College of Statistics and Mathematics, Yunnan University of Finance and Economics, Kunming, Yunnan 650221, China 2Department of Mathematics Education, Kyungnam University, Masan, Kyungnam 631-701, South Korea ${ }^{3}$ Department of Applied Mathematics, The Hong Kong Polytechnic University, Hong Kong

\section{Authors' contributions}

S-SC and JKK conceived the study and participated in its design and coordination. JKK and HWJL suggested many good ideas that are useful for achievement this paper and made the revision. JKK and CKC prepared the manuscript initially and performed all the steps of proof in this research. All authors read and approved the final manuscript.

\section{Competing interests}

The authors declare that they have no competing interests.

Received: 23 May 2011 Accepted: 16 February 2012 Published: 16 February 2012

\section{References}

1. Goebel, K, Kirk, WA: A fixed point theorem for asymptotically nonexpansive mappings. Proc Am Math Soc. 35, 171-174 (1972). doi:10.1090/S0002-9939-1972-0298500-3

2. Bruck, R, Kuczumow, T, Reich, S: Convergence of iterates of asymptotically nonexpansive mappings in Banach spaces with the uniform Opial property. Colloq Math. 65(2):169-179 (1993)

3. Kirk, WA: Fixed point theorems for non-Lipschitzian mappings of asymptotically nonexpansive type. Israel J Math. 17(4):339-346 (1974). doi:10.1007/BF02757136

4. Alber, Yal, Chidume, CE, Zegeye, $\mathrm{H}$ : Approximating fixed points of total asymptotically nonexpansive mappings. Fixed Point Theory Appl 2006, 20 (2006). Article ID 10673

5. Quan, J, Chang, SS, Long, J: Approximation of asymptotically quasi-nonexpansive-type mappings by finite steps iterative sequences. Fixed Point Theory Appl 2006 (2006). Article ID 70830

6. Shahzad, N, Udomene, A: Approximating common fixed points of two asymptotically quasi-nonexpansive mappings in Banach spaces. Fixed Point Theory Appl 2006 (2006). Article ID 18909, 10

7. Ghosh, MK, Debnath, L: Convergence of Ishikawa iterates of quasi-nonexpansive mappings. J Math Anal Appl. 207(1):96-103 (1997). doi:10.1006/jmaa.1997.5268

8. Sun, Z-H: Strong convergence of an implicit iteration process for a finite family of asymptotically quasi-nonexpansive mappings. J Math Anal Appl. 286(1):351-358 (2003). doi:10.1016/S0022-247X(03)00537-7

9. Chang, S-S, Tan, KK, Lee, HWJ, Chan, CK: On the convergence of implicit iteration process with error for a finite family of asymptotically nonexpansive mappings. J Math Anal Appl. 313(1):273-283 (2006). doi:10.1016/j.jmaa.2005.05.075

10. Jung, JS: Iterative approaches to common fixed points of nonexpansive mappings in Banach spaces. J Math Anal Appl. 302(2):509-520 (2005). doi:10.1016/j.jmaa.2004.08.022

11. Shioji, N, Takahashi, W: Strong convergence of approximated sequences for nonexpansive mappings in Banach spaces. Proc Am Math Soc. 125(12):3641-3645 (1997). doi:10.1090/S0002-9939-97-04033-1

12. Suzuki, T: Strong convergence of Krasnoselskii and Mann's type sequences for one-parameter nonexpansive semigroups without Bochner integrals. J Math Anal Appl. 305(1):227-239 (2005). doi:10.1016/j.jmaa.2004.11.017

13. Chidume, CE, Ofoedu, EU: Approximation of common fixed points for finite families of total asymptotically nonexpansive mappings. J Math Anal Appl. 333(1):128-141 (2007). doi:10.1016/j.jmaa.2006.09.023 
14. Chidume, $C E$, Ofoedu, EU: A new iteration process for approximation of common fixed points for finite families of total asymptotically nonexpansive mappings. Intern J Math Math Sci2009, 17. Article ID 615107, doi:10.1155/2009/615107

15. Chidume, CE, Ali, B: Approximation of common fixed points for finite families of nonself asymptotically nonexpansive mappings in Banach spaces. J Math Anal Appl. 326(2):960-973 (2007). doi:10.1016/j.jmaa.2006.03.045

16. Nammanee, K, Noor, MA, Suantai, S: Convergence criteria of modified Noor iterations with errors for asymptotically nonexpansive mappings. J Math Anal Appl. 314(1):320-334 (2006). doi:10.1016/j.jmaa.2005.03.094

17. Suantai, S: Weak and strong convergence criteria of Noor iterations for asymptotically non-expansive mappings. J Math Anal Appl. 311(2):506-517 (2005). doi:10.1016/j.jmaa.2005.03.002

18. Chang, S-S, Joseph Lee, HW, Chan, CK: On Reich's strong convergence theorem for asymptotically nonexpansive mappings in Banach spaces. Nonlinear Anal.: Theory, Methods Appl. 66(11):2364-2374 (2007). doi:10.1016/j. na.2006.03.025

19. Schu, J: Iterative construction of fixed points of asymptotically nonexpansive mappings. J Math Anal Appl. 158(2):407-413 (1991). doi:10.1016/0022-247X(91)90245-U

20. Chang, SS, Kim, JK, Wang, XR: Modified block iterative algorithm for solving convex feasibility problems in Banach spaces. J Inequal Appl2010, 14. Article ID 869684, doi:10.1155/2010/869684

doi:10.1186/1029-242X-2012-37

Cite this article as: Chang et al:: A generalization and improvement of Chidume theorems for total

asymptotically nonexpansive mappings in Banach spaces. Journal of Inequalities and Applications 2012 2012:37.

\section{Submit your manuscript to a SpringerOpen ${ }^{\odot}$} journal and benefit from:

- Convenient online submission

- Rigorous peer review

- Immediate publication on acceptance

- Open access: articles freely available online

- High visibility within the field

- Retaining the copyright to your article

Submit your next manuscript at $\boldsymbol{s p r i n g e r o p e n . c o m ~}$ 